\title{
Spontaneous transformation of human granulosa cell tumours into an aggressive phenotype: a metastasis model cell line Misa Imai1,2, Miho Muraki1 ${ }^{1}$ Kiyoshi Takamatsu ${ }^{3}$, Hidekazu Saito1, Motoharu Seiki² and Yuji Takahashi*1
}

Address: ${ }^{1}$ Division of Reproductive Medicine, Department of Perinatal Medicine and Maternal Care, National Center for Child Health and Development, Tokyo 157-8535, Japan, ${ }^{2}$ Division of Cancer Cell Research, Institute of Medical Science, the University of Tokyo, Tokyo 108-8639, Japan and ${ }^{3}$ Department of Obstetrics and Gynecology, Tokyo Dental College Ichikawa General Hospital, Chiba 272-8513, Japan

Email: Misa Imai - misa.imai@helsinki.fi; Miho Muraki - aa087121@mail.ecc.u-tokyo.ac.jp; Kiyoshi Takamatsu - ktakamatsu@tdc.ac.jp; Hidekazu Saito - saitou-hi@ncchd.go.jp; Motoharu Seiki - mseiki@ims.u-tokyo.ac.jp; Yuji Takahashi* - takahashi-yj@ncchd.go.jp

* Corresponding author

Published: 4 November 2008

BMC Cancer 2008, 8:319 doi:10.1/86/147|-2407-8-319
Received: 24 October 2007

Accepted: 4 November 2008

This article is available from: http://www.biomedcentral.com/I47I-2407/8/3I9

(c) 2008 Imai et al; licensee BioMed Central Ltd.

This is an Open Access article distributed under the terms of the Creative Commons Attribution License (http://creativecommons.org/licenses/by/2.0), which permits unrestricted use, distribution, and reproduction in any medium, provided the original work is properly cited.

\begin{abstract}
Background: Granulosa cell tumours (GCTs) are frequently seen in menopausal women and are relatively indolent. Although the physiological properties of normal granulosa cells have been studied extensively, little is known about the molecular mechanism of GCT progression. Here, we characterise the unique behavioural properties of a granulosa tumour cell line, KGN cells, for the molecular analysis of GCT progression.
\end{abstract}

Methods: Population doubling was carried out to examine the proliferation capacity of KGN cells. Moreover, the invasive capacity of these cells was determined using the in vitro invasion assay. The expression level of tumour markers in KGN cells at different passages was then determined by Western blot analysis. Finally, the growth and metastasis of KGN cells injected subcutaneously (s.c.) into nude mice was observed 3 months after injection.

Results: During in vitro culture, the advanced passage KGN cells grew 2-fold faster than the early passage cells, as determined by the population doubling assay. Moreover, we found that the advanced passage cells were 2 -fold more invasive than the early passage cells. The expression pattern of tumour markers, such as p53, osteopontin, BAX and BAG-I, supported the notion that with passage, KGN cells became more aggressive. Strikingly, KGN cells at both early and advanced passages metastasized to the bowel when injected s.c. into nude mice. In addition, more tumour nodules were formed when the advanced passage cells were implanted.

Conclusion: $\mathrm{KGN}$ cells cultured in vitro acquire an aggressive phenotype, which was confirmed by the analysis of cellular activities and the expression of biomarkers. Interestingly, KGN cells injected s.c. are metastatic with nodule formation occurring mostly in the bowel. Thus, this cell line is a good model for analysing GCT progression and the mechanism of metastasis in vivo. 


\section{Background}

GCTs are a relatively uncommon neoplasm; the incidence of GCTs ranges from 1.6-3.0\% in all cases of ovarian tumour and comprises about $10 \%$ of all cases of ovarian cancer [1]. They belong to the sex-cord stromal tumours [2], and are classified as juvenile or adult, although the majority of GCTs occur in menopausal women [3]. GCTs are known to retain numerous characteristics of native granulosa cells, such as the expression of active FSH receptor, inhibin, and estrogen [4-6]. Although GCTs have a malignant potential, they are often indolent and have a propensity for late recurrence $[7,8]$. Up to $53 \%$ of all cases lead to metastases within 5 years and studies encompassing long-term follow-up have shown high mortality rates, with about $50 \%$ of women dying from the disease within 20 years of diagnosis $[9,10]$. Although there have been extensive studies on the biology of normal granulosa cells $[11,12]$, much knowledge of the molecular mechanism by which transition from promotion to the progression stage occurs in GCTs remains unknown.

To date, only seven human granulosa cell lines have been established, [1,13-18] although several animal granulosa cell-derived cell lines have been reported [14]. Of these, KGN cells were generated from a GCT that recurred in the pelvic region, and were shown to have detectable aromatase activity [1]. KGN cells have an abnormal karyotype $(45, \mathrm{XX}, 7 \mathrm{q}-,-22)$ which is probably related to the tumourigenic character of this granulosa cell, as frequent abnormalities in chromosome 7 have been reported in ovarian tumours $[19,20]$. Interestingly, KGN cells revealed a unique characteristic and grew progressively faster during passages in our preliminary experiment.

Here, we investigated the specific characteristics of KGN cells towards understanding the molecular pathogenesis of GCTs. Because KGN cells grew much faster after passages in culture, we investigated their cellular characteristics, such as proliferation capacity and invasiveness, during passages in vitro. We then investigated the behaviour of these cells in vivo with the use of subcutaneous xenografts at different passages.

\section{Methods \\ Reagents}

Hoechst 33342 and Mitomycin C from Streptomyces Caespitosus, luteinizing hormone ( $\mathrm{LH}$ ) and follicle stimulating hormone (FSH) were purchased from Sigma Chemical Co. (St. Louis, MO, USA). Mouse monoclonal antibody against p53 and osteopontin and rabbit polyclonal antibodies against BAG-1 and BAX were purchased from Santa Cruz Biotechnology Inc. (Santa Cruz, CA, USA). Goat anti-mouse IgG-HRP and goat anti-rabbit IgG-HRP were purchased from Pierce Chemical Co. Ltd. (Woburn, MA,
USA) and Chemicon International Co. Ltd. (Temecula, CA, USA), respectively.

\section{Cell Culture}

KGN cells were obtained from RIKEN Bioresource Center (Tsukuba, Japan). Early (fewer than P10) and advanced (more than P47) passage KGN cells were maintained as described previously [21]. For detailed characterisation, the cells were cultured in a medium supplemented with $10 \%$ charcoal/dextran-treated FBS (delipidated FBS, Thermo Fishers Scientific Inc., South Logan, UT, USA), 0.1 $\mathrm{IU} / \mathrm{ml} \mathrm{LH}$ or $1 \mathrm{IU} / \mathrm{ml} \mathrm{FSH}$. Cells were routinely passaged after brief exposure to $0.25 \%$ trypsin with $0.02 \%$ EDTA in PBS (-).

\section{Evaluation of cellular morphology, proliferation and invasion}

The morphology of KGN cells was observed under a phase-contrast microscope (IX-71; Olympus, Tokyo, Japan). The cellular proliferation was measured by population doubling of KGN cells in a logarithmic growth phase at a starting concentration of $2 \times 10^{5}$ cells/dish in 60 mm Petri dishes (Falcon, BD Japan, Tokyo, Japan). The number of KGN cells was determined at $24 \mathrm{~h}$ interval for 4 days while changing the medium every other day. To determine the proliferation rate of KGN cells at Day 4, a colorimetric TetraColor ONE ELISA kit (SEIKAGAKU CORPORATION, Tokyo, Japan) was utilised. Cells were initially seeded at a density of $1 \times 10^{4}$ cells/well in 96-well plates and the subsequent assay was carried out according to the manufacturer's instructions. For invasion assay, KGN cells $\left(1 \times 10^{5}\right.$ cells/well $)$ suspended in serum-free medium were seeded on the upper chamber coated with Matrigel $(200 \mu \mathrm{g} / \mathrm{ml}$, Becton Dickinson, San Jose, CA, USA). FBS (10\%) was added to the medium in the lower chamber and incubated for $12 \mathrm{~h}$ to allow cell invasion, and then cells were fixed with $100 \%$ methanol. To exclude the possibility that invasiveness was overestimated by distinct proliferation capacity of different passage cells, they were treated with $10 \mu \mathrm{g} / \mathrm{ml}$ Mitomycin $\mathrm{C}$ for $2 \mathrm{~h}$ at $37^{\circ} \mathrm{C}$ in a $\mathrm{CO}_{2}$ incubator and subjected to the invasion assay. The cells retained in the upper chamber were scraped off and stained with $10 \mu \mathrm{M}$ Hoechst 33342 for $30 \mathrm{~min}$ at room temperature. The number of cells that invaded through the chamber was counted using an epi-fluorescence microscope. The experiments described above were triplicated.

\section{Chromosome analysis}

The chromosomes were examined in exponentially growing early and advanced passage KGN cells (early: P6; advanced: P53) in an in vitro culture. The karyotype of 10 KGN cells was analysed by standard trypsin G-banding, as described previously [1]. 


\section{Western blot analysis}

Cells were lysed in RIPA buffer containing protease inhibitor cocktails I and II (1:100 dilution, Sigma Chemical $\mathrm{Co}$ ) for $2 \mathrm{~h}$ at $4^{\circ} \mathrm{C}$, and the insoluble materials were removed by centrifugation $(15,000 \mathrm{rpm}, 15 \mathrm{~min})$. The protein concentration of samples was determined using a micro BCA assay kit (Pierce Chemical Co. Ltd., Rockford, IL, USA). Ten or fifty micrograms of samples per lane were separated on a $12.5 \%$ reducing SDS polyacrylamide gel, and transferred onto a PVDF membrane (Immobilon-P, Millipore Japan, Tokyo, Japan). After blocking with 10\% goat serum plus 90\% Blockace (SnowBrand, Tokyo, Japan) at room temperature for $1 \mathrm{~h}$, the membranes were treated with the primary antibody and subsequently with the secondary antibody. SuperSignal West Femto Maximum Sensitivity Substrate (Pierce, Rockford, IL, USA) was used for visualisation, and the signal was developed on an X-ray film (Amersham Bioscience, Piscataway, NJ). The band intensity of each protein was measured using ADOBE Photoshop Element 3.0 software and the background was subtracted. It was then divided by the band intensity of $\beta$-actin for normalisation.

\section{Tumour xenografts}

The experiments were approved by the Animal Ethics Committee at the National Center for Child Health and Development, Japan. Six-week-old female BALB/c Foxn1/ Foxn1 mice (nude mice) were purchased from Sankyo Labo Service Co. Ltd. (Tokyo, Japan). The early or advanced passage KGN cells $\left(5 \times 10^{6}\right.$ cells) were harvested, resuspended in $200 \mu \mathrm{l}$ of PBS, and injected s.c. into both flanks of each mouse (early; $n=9$, advanced; $n=9$ ). Mice were euthanized and examined for tumour generation after 3 months, and the number of nodules formed in the bowel was counted. The experiments were quadruplicated.

\section{Histological evaluation}

For light microscopic analysis, the metastases formed in the bowel were fixed with $4 \%$ formaldehyde, paraffinembedded, sectioned at $4 \mu \mathrm{m}$ intervals and stained with hematoxylin-eosin.

\section{Semi-quantitative RT-PCR analysis}

The small intestine with or without metastases was obtained from four mice in each group (control, the 'early', and the 'advanced' groups) and total RNA was isolated with the use of ISOGEN RNA isolation reagent (Nippon Gene Co. Ltd., Tokyo, Japan). Reverse transcription was conducted, as described previously [21]. The expression of p53 was monitored by PCR amplification. The specific primers for human p53 and GAPDH and cycles used for each gene were as follows; p53 forward primer: CAGCCAAGTCTGTGACTTGCACGTAC, p53 reverse primer: CTATGTCGAAAAGTGTTTCTGTCATC, 35 cycles;
GAPDH forward primer: ACCACAGTCCATGCCATCAC, GAPDH reserve primer: TCCACCACCCTGTTGCTGTA, 28 cycles. The conditions for PCR amplification were: initial denaturation at $94^{\circ} \mathrm{C}$ for $5 \mathrm{~min}$, followed by the indicated cycles of denaturation at $94^{\circ} \mathrm{C}$ for $45 \mathrm{~s}$, annealing at $57^{\circ} \mathrm{C}$ for $45 \mathrm{~s}$, and elongation at $72^{\circ} \mathrm{C}$ for $1 \mathrm{~min}$, with a final extension of $72^{\circ} \mathrm{C}$ for $15 \mathrm{~min}$. The image analysis of the PCR product was performed as described previously [21].

\section{Statistical analysis}

The average data on population doubling, proliferation, invasion and metastasis were presented as means with SEM from three independent experiments. Statistical analyses were conducted by Student's or modified $t$-test using Microsoft Excel software. Differences were considered statistically significant when $\mathrm{P}<0.05$.

\section{Results \\ Characterisation of $\mathrm{KGN}$ cells in vitro}

KGN cells appeared to grow faster during passages in our preliminary experiments. For detailed characterisation of KGN cells, early and advanced passage cells were cultured, and the proliferation capacity was monitored. Growth of the advanced passage cells turned out to be significantly faster than that of the early passage cells, determined by population doubling evaluation (Fig 1A and 1B, about 2fold increase at Days 3 and $4, \mathrm{P}<0.05, \mathrm{P}<0.01)$. The behavioural changes of KGN cells at different passages occurred without any morphological changes at Days 1 and 4 (Fig 1A).

Next, we conducted an in vitro invasion assay to assess the characteristic features of the tumours. Along with increased proliferative activity, the advanced passage cells were 2-fold more invasive than the early passage cells (Fig $1 \mathrm{C}, \mathrm{P}<0.01)$. Since the advanced passage cells were more proliferative than the early passage cells, KGN cells were treated with Mitomycin $\mathrm{C}$ to prevent proliferation during the invasion assay. Loss of proliferative capacity of the advanced passage cells was confirmed by the TetraColor ONE proliferation assay (OD450; untreated early passage cells: 0.10; untreated advanced: 0.18; treated early: 0.09; treated advanced 0.10). Under the conditions of the assay, the advanced passage cells remained more invasive than the early passage cells (Fig $1 \mathrm{D}, \mathrm{P}<0.01$ ), suggesting that the increased invasiveness was not related to proliferation.

Because serum factors and hormones may be involved in GCT progression, KGN cells were cultured in a medium containing delipidated FBS, $\mathrm{LH}$ or FSH, and subjected to the proliferation assay. As shown in Fig 2, none of these treatments affected the characteristics of the early and advanced passage cells. 


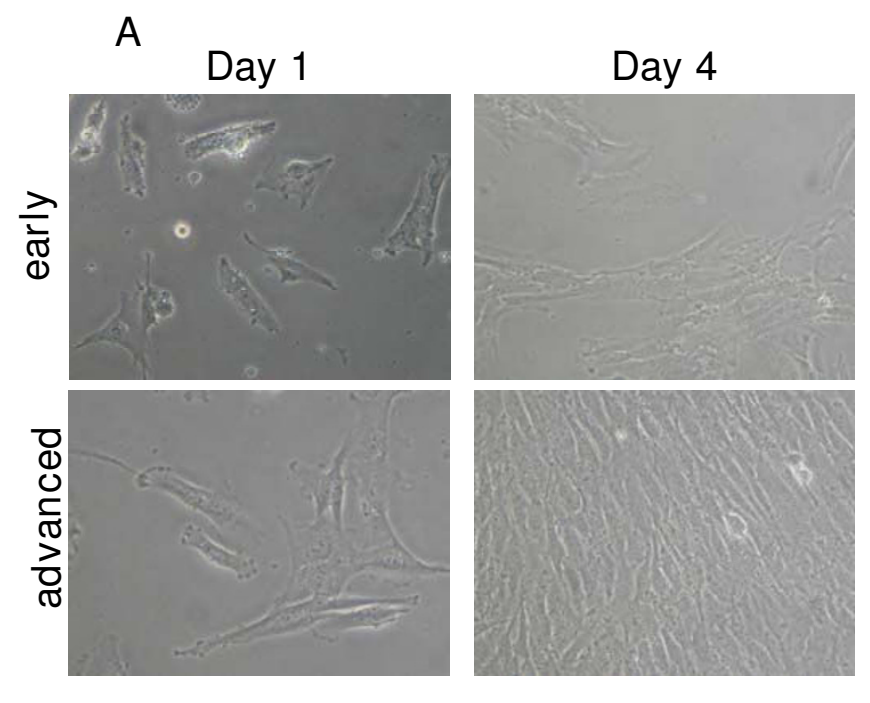

B
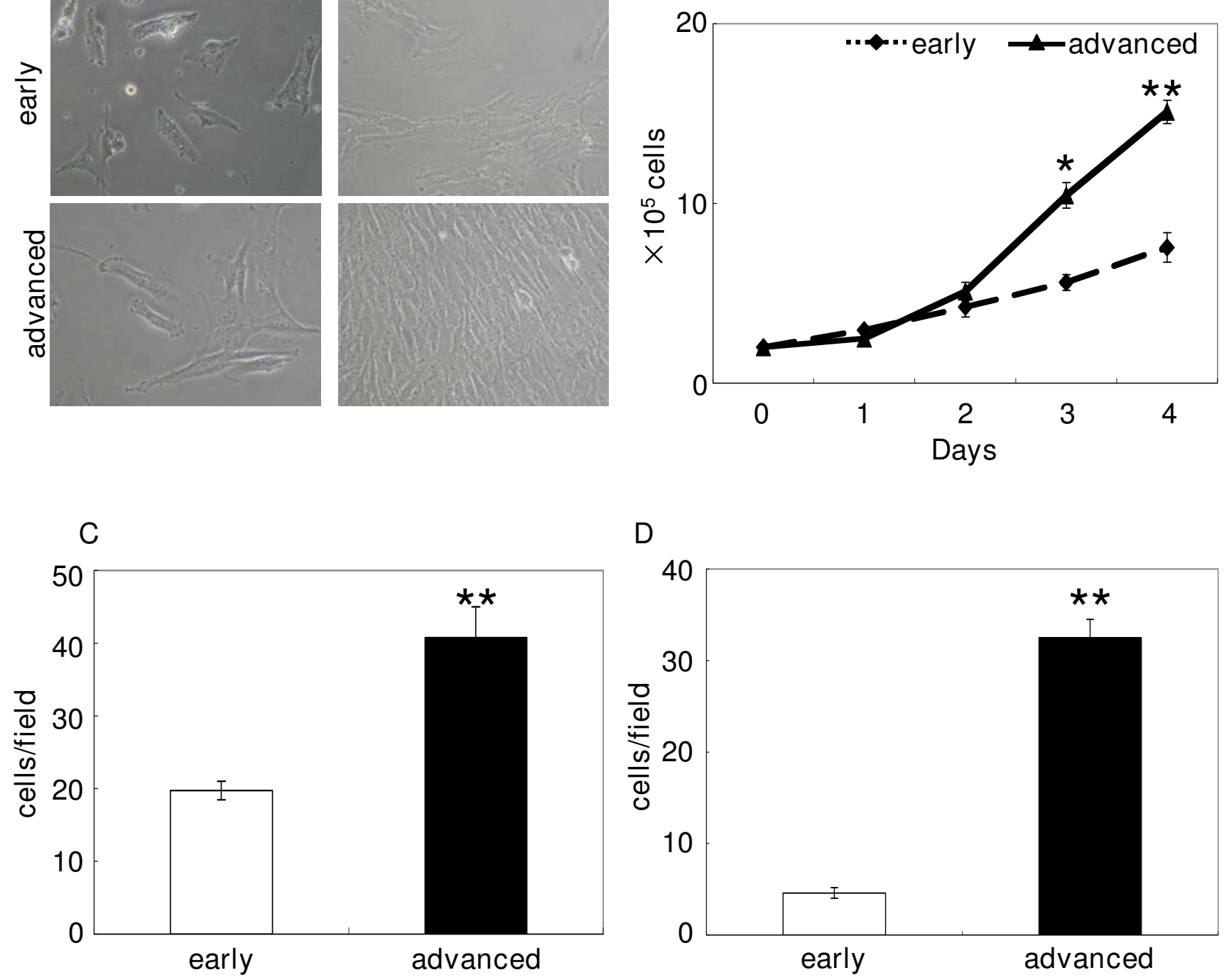

Figure I

Characterization of KGN cells at different passages. (A) Morphology of KGN cells at Days I and 4 (P9 vs. P58). (B) Population doubling measured for 4 days using the early and advanced passage KGN cells seeded at $2 \times 10^{5}$ cells/dish ( $P 9$ vs. P58). (C, D) Invasiveness of different passage KGN cells (P6 vs. P53). Cells in serum-free medium at a concentration of I $\times 10^{5}$ cells/well were subjected to an invasion assay using transwell chambers coated with Matrigel for $12 \mathrm{~h}$ (C; normal cells, D; Mitomycin C-treated cells). The proliferation of Mitomycin C-treated cells was blocked, as determined by the TetraColor One proliferation assay. All experiments were triplicated and the data are shown as the mean number with SEM. Statistical difference was analysed by Student's $t$-test ( $* \mathrm{P}<0.05)$.

\section{Karyotype analysis}

G-banded karyotype analyses of 10 early and advanced KGN cells revealed that all the cells exhibited 45 chromosomes (data not shown), as described previously [1].

\section{Expression of various tumour markers in KGN cells at different passages}

Subsequently, we examined the expression level of malignant tumour markers in the early and advanced passage cells (Fig 3A, B). Initially, we determined the expression level of p53, which has been reported to be a prognostic marker of metastasis in granulosa cell tumours $[9,22]$. As expected, the expression level of p53 was up-regulated in 


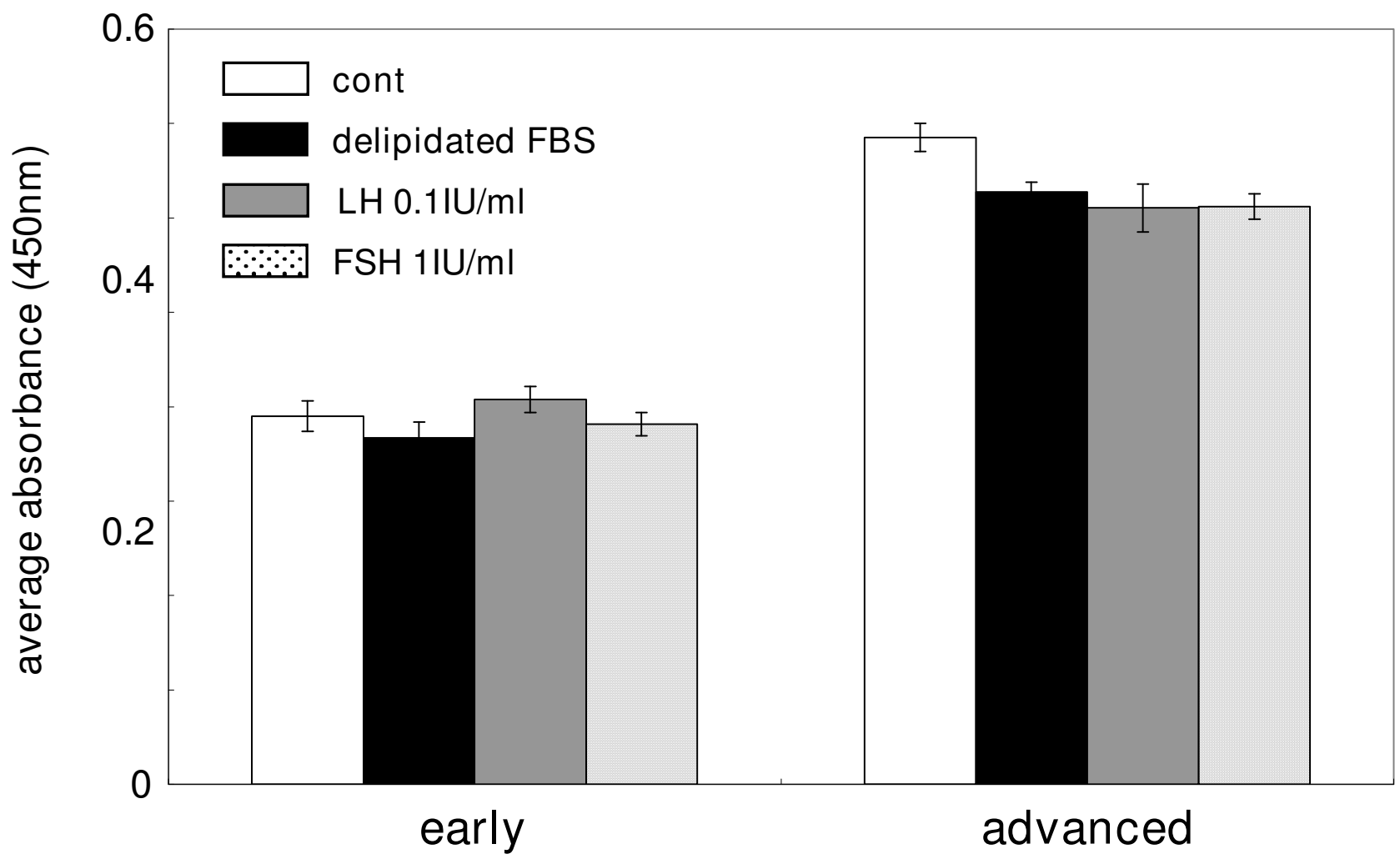

Figure 2

Proliferation of KGN cells at different passages. The early (P6) and advanced (P58) passage KGN cells were cultured in $10 \%$ delipidated FBS, $0.1 \mathrm{IU} / \mathrm{ml} \mathrm{LH}$, or I IU/ml FSH, seeded at I $\times 10^{4}$ cells/well in 96 -well plates and subjected to the proliferation assay. The experiments were triplicated and the data are shown as the mean absorbance with SEM (at OD $450 \mathrm{~nm}$ ). Statistical analysis was conducted using Student's $t$-test.

the advanced passage cells. Next, we performed immunoblots for osteopontin, which is a biomarker of tumour progression [23], and found that it markedly increased in the advanced passage cells. Furthermore, we examined the expression of BAX and BAG-1, which are known biomarkers of apoptosis [24]. As expected, BAX was up-regulated, whereas BAG-1 was down-regulated in the advanced passage cells, suggesting that the advanced passage cells might be resistant to apoptosis. These results strongly indicate that KGN cells became aggressive during passages in vitro.

\section{Tumour growth in vivo}

Further characterisation of KGN cells was performed using an in vivo tumour growth assay in nude mice. As shown in Fig 4A, the xenograft of the advance passage cells developed faster than that of the early passage cells at the region where KGN cells were injected, and larger clumps under the skin were observed (in the small windows of Fig 4A). More interestingly, KGN cells at both the early and advanced passages metastasized from the subcutaneous transplanted region to the bowel, especially in the submucosa of the small intestine, but not to the other tissues (metastases in the bowel were seen in 7 out of 9 mice transplanted) (Fig 4B). Although an increased number of nodules were formed in the bowel by transplantation of the advanced passage cells (Fig 4C, P $<0.05$ ), the size of nodules obtained using both passage cells was similar ( 3 $\mathrm{mm} \times 3 \mathrm{~mm}$ ).

To confirm the origin of nodules, the expression of a GCTspecific marker in the nodules was examined by RT-PCR using human-specific primers. As shown in Fig 4D, human p53 mRNA was found to be expressed in the nodules, suggesting that the nodules originated from KGN cells. Moreover, histological analysis revealed that the cells at both passages exhibited a coffee bean-like nuclear appearance, which is typically observed in specimens of granulosa cell origin (Fig 5). These results demonstrated that KGN cells metastasized from the subcutaneous region to the bowel. 
A
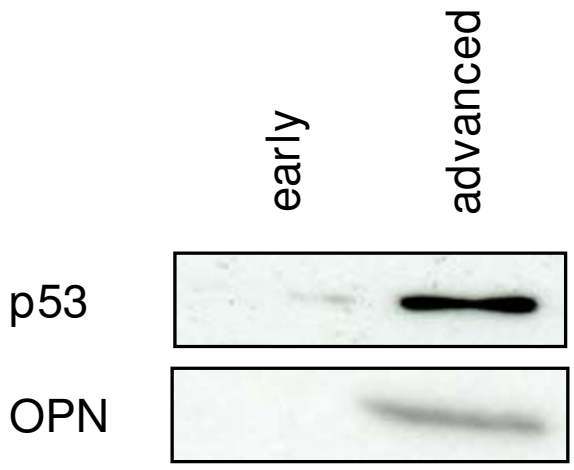

Bag1

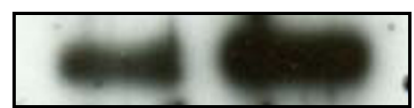

Bax

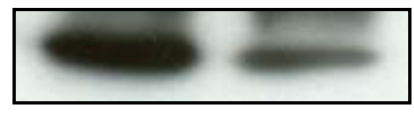

Actin

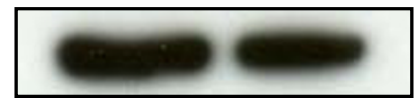

$\mathrm{B}$

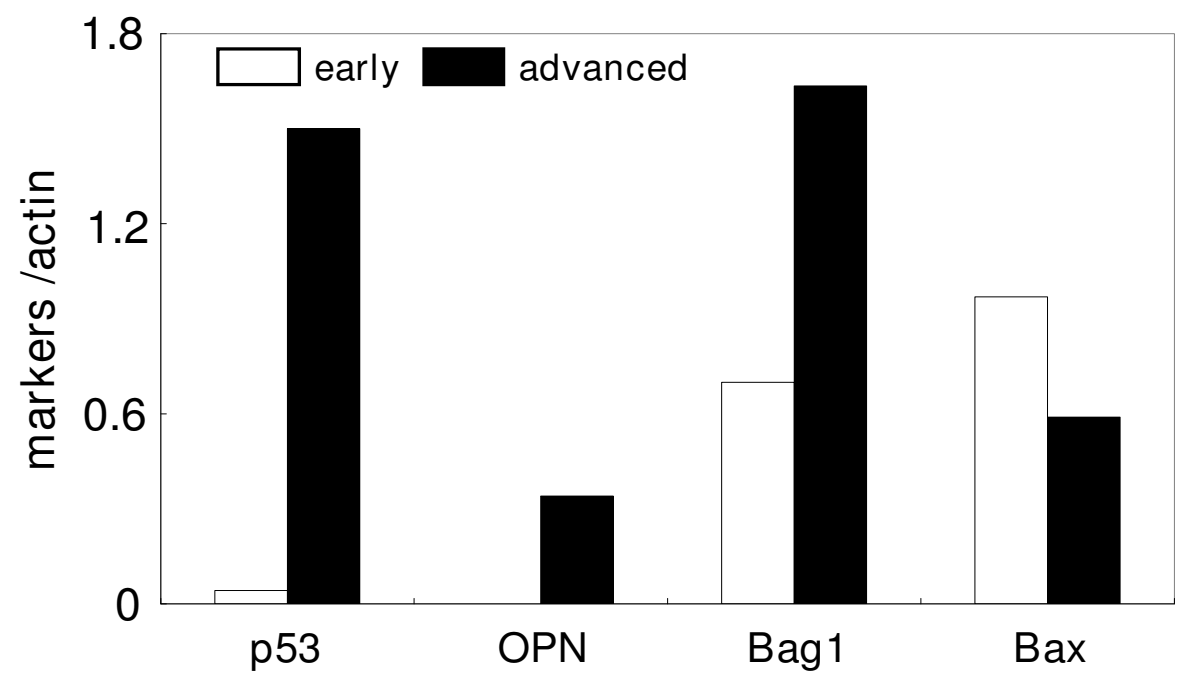

Figure 3

Expression of tumour markers in KGN at different passages. Western blot analysis of KGN cells at P7 and P5I was conducted to examine the expression level of $\mathrm{p} 53$, osteopontin, BAX and BAG-I. Ten $\mu \mathrm{g}$ (for BAX and BAG-I) or $50 \mu \mathrm{g}$ (for p53 and osteopontin) of whole cell extract were separated on a $12.5 \%$ reducing gel. The lower panel represents the mean intensity of each band normalised by dividing with the intensity of $\beta$-actin. 
A
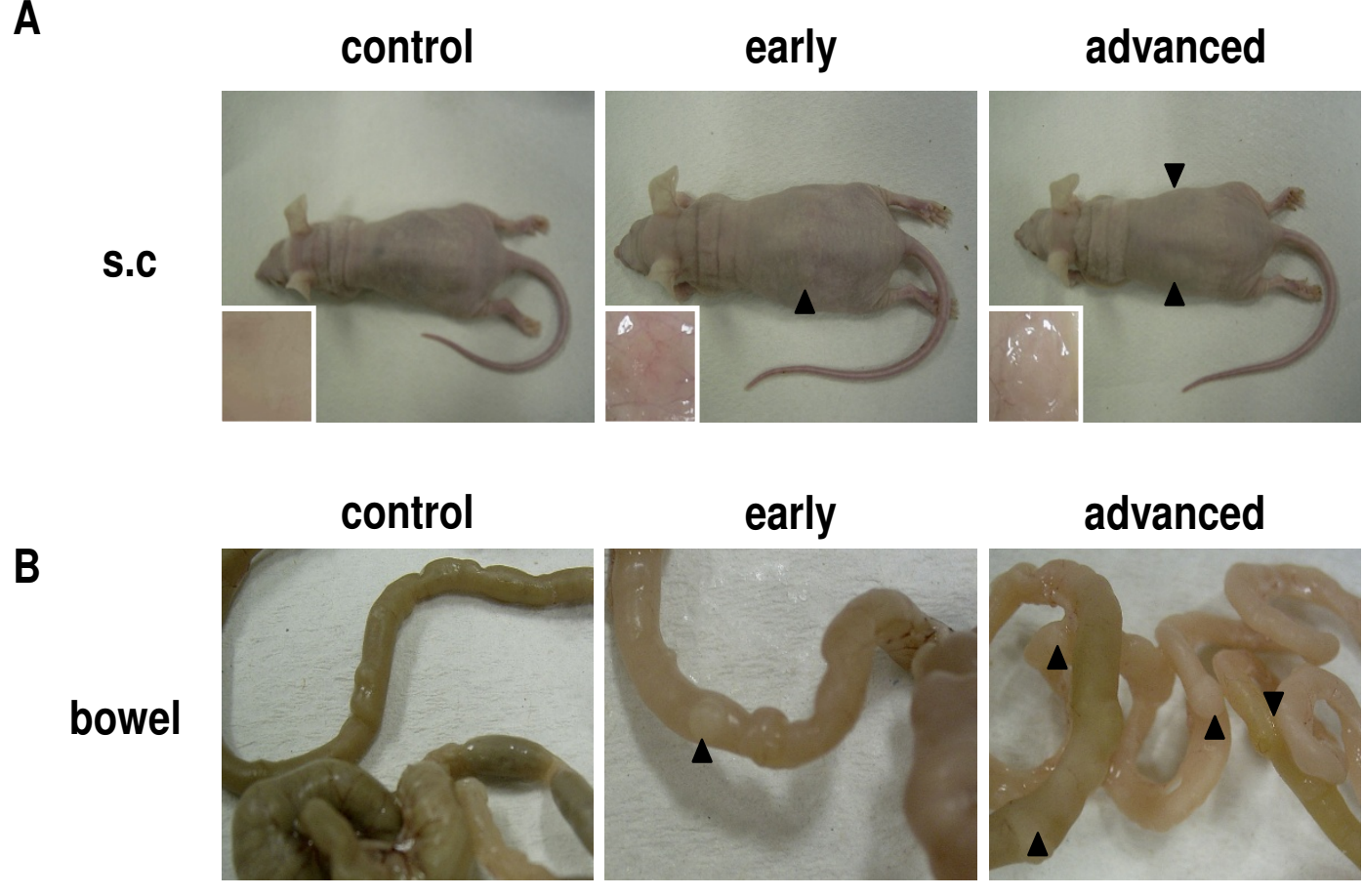

C

D
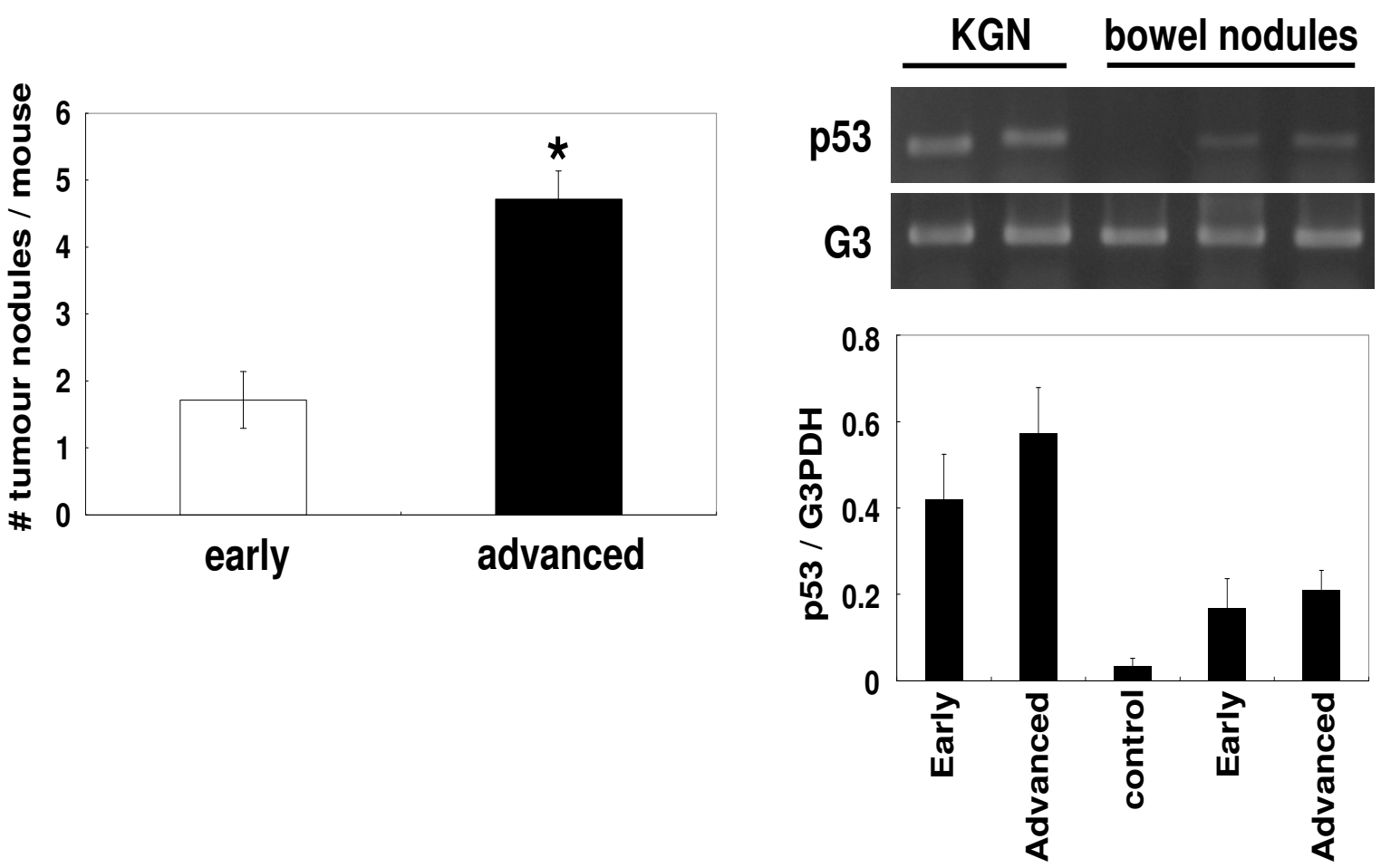

Figure 4 (see legend on next page) 
Figure 4 (see previous page)

Growth and metastases of KGN cells in nude mice. KGN cells at the early (P7) and advanced (P58) passages were transplanted in the flanks of nude mice at a concentration of $5 \times 10^{6}$ cells. After 3 months, the growth of KGN cells at the injected region and metastases in the bowel were examined. (A) Growth of KGN cells (P7 and P59) at the injected regions shown by arrowheads. Tumour growth under the skin is shown in the enlarged windows. (B) Metastases of KGN cells in the bowel of nude mice. Arrowheads indicate metastases (nodules). The metastases were about $3 \mathrm{~mm} \times 3 \mathrm{~mm}$ in size and were observed in 7 out of 9 mice. (C) The number of tumour nodules formed in the bowel was counted from 7 nude mice. Data are shown as the mean number of nodules with SEM. Statistical difference was analysed by Student's $t$-test (*P < 0.05). These experiments were quadruplicated. (D) Semi-quantitative RT-PCR analysis of human p53 in intestines with or without tumour nodules. Total RNA was isolated from the small intestine with or without nodules in each experimental group, and PCR analysis was performed using human-specific primers for $\mathrm{p} 53$. The upper panel represents a typical digital photograph taken on a transilluminator. Lower panel represents the averaged band intensity of p53 with SEM from four independent experiments.

\section{Discussion}

In the previous study, KGN cells were shown to retain properties of normal granulosa cells, such as aromatase activity and progesterone synthesis [1]. Despite the fact that KGN cells can be maintained in more than 100 passages, their native properties are unchanged during passages. Moreover, we confirmed progesterone synthesis in the advanced passage cells in response to CAMP, and that chromosomal instability did not occur during passages determined by G-band analysis (data not shown). Therefore, the transformation of KGN cells during passages occurs without loss of their native characteristics.

The mechanism responsible for the phenotypic transformation of the cells during passages remains uncertain. One possibility is that a minor population of aggressive GCTs included in the early passage cells prevailed during passages, resulting in an overall aggressive character. Although cloning of the early passage cells ( 7 clones examined) did not show any changes in phenotype among the clones (data not shown), this possibility could not be ruled out. The second possibility is that oxidative stress gained during in vitro culture may have prompted the transformation. Although administration of hydrogen peroxide to the culture of KGN cells did not affect their behaviour in our study (data not shown), it is likely that oxidative stress during in vitro culture may induce genome instability and mutation in these cells. The third possibility is that hormones, such as estrogen and progesterone, secreted from KGN cells influence the transformation. Although high expression level of estrogen receptor $\beta$ $(\mathrm{ER} \beta)$, a potent suppressor of proliferation, has been reported in GCTs [25], direct interaction between ER $\beta$ and NF- $\kappa \mathrm{B}$ might be required for GCTs survival [26]. However, exogenous administration of hormones, such as estrogen, LH and FSH, to the culture did not enhance the transformation. Another possibility might be that cytokines and other growth factors present in FBS may influence the cellular phenotype, although we determined that at least EGF did not influence on the proliferation of KGN cells (data not shown). Therefore, further analysis is required to elucidate the exact mechanism involved in the transformation of KGN cells in vitro.

Spontaneous changes in cellular characteristics during in vitro culture are, more or less, common among different cell types. In fact, several cell lines have been reported to undergo in vitro transformation into a malignant phenotype [27-29]. Conversely, human tumours implanted s.c. in nude mice are known to have little metastatic capability [30]. However, KGN cells were found to be metastatic with nodule formation occurring mostly in the bowel. Because the nodules were formed in the submucosa of the small intestine, they must have not metastasized peritoneally. However, the route of KGN cells to the bowel remains uncertain. Although it seems that the metastases develop slowly since the tumour nodules of KGN cells remained small in size after 3 months of transplantation and histological evaluation ( $3 \mathrm{~mm} \times 3 \mathrm{~mm})$, this cell line may be useful for research on metastasis.

\section{Conclusion}

We characterised KGN cells as a malignant tumour model of GCTs. Continuously cultivated KGN cells acquire an aggressive phenotype, confirmed by the analysis of cellular activities and the expression of biomarkers. More strikingly, KGN cells injected under the skin were metastatic with nodule formation occurring mostly in the bowel. Thus, this cell line is a good model for analysing GCT progression and the mechanisms of metastasis.

\section{Competing interests}

The authors declare that they have no competing interests.

\section{Authors' contributions}

MI conducted cell culture, the analysis of cellular behaviour and prepared the manuscript. MM performed Western blot analysis. KT designed the experiments on the histological analysis. HS performed in the histological evaluation. MS participated in the design of study. YT coordinated the study and finalised the preparation of the 
$\times 40$
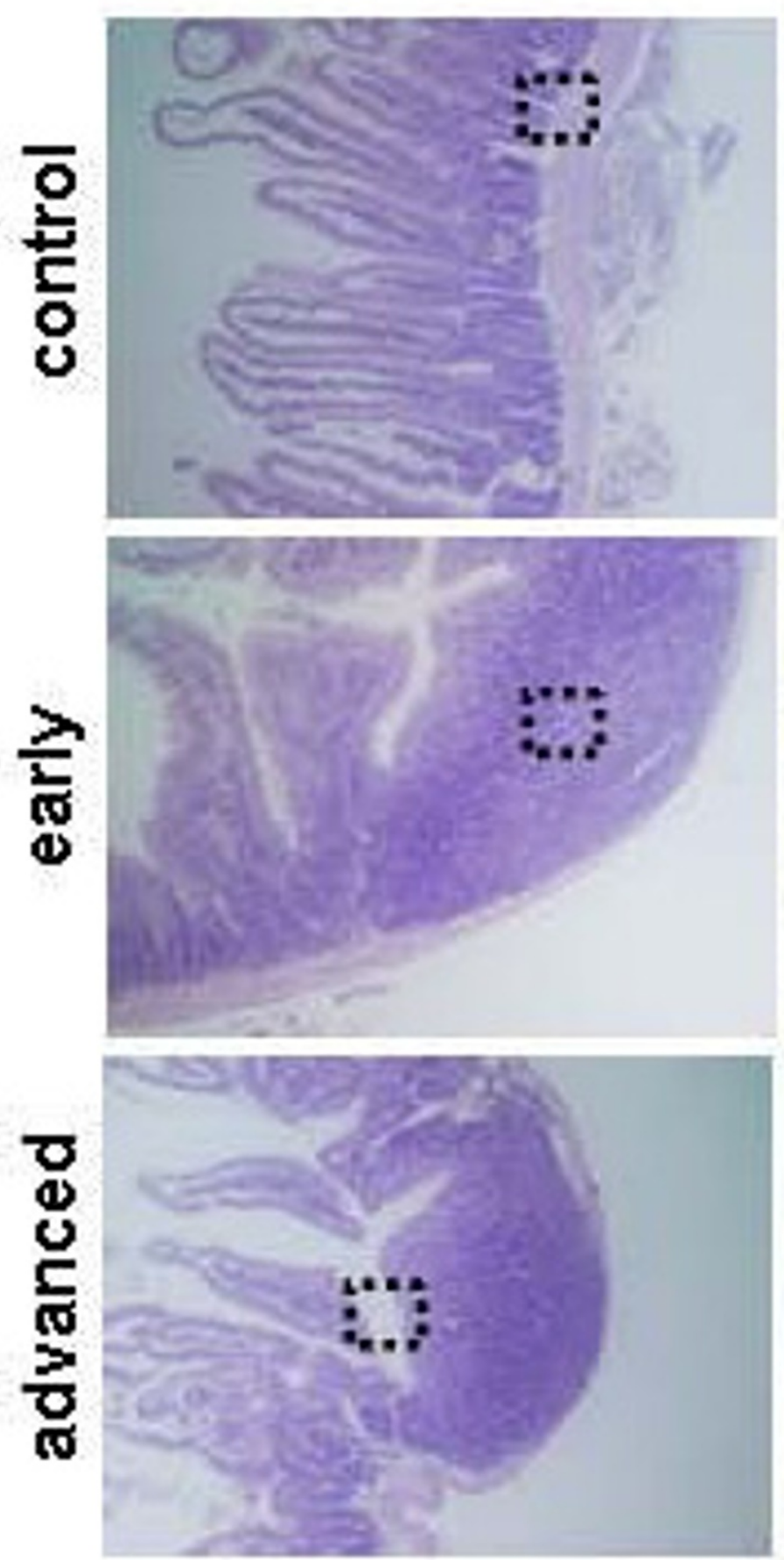

$\times 400$
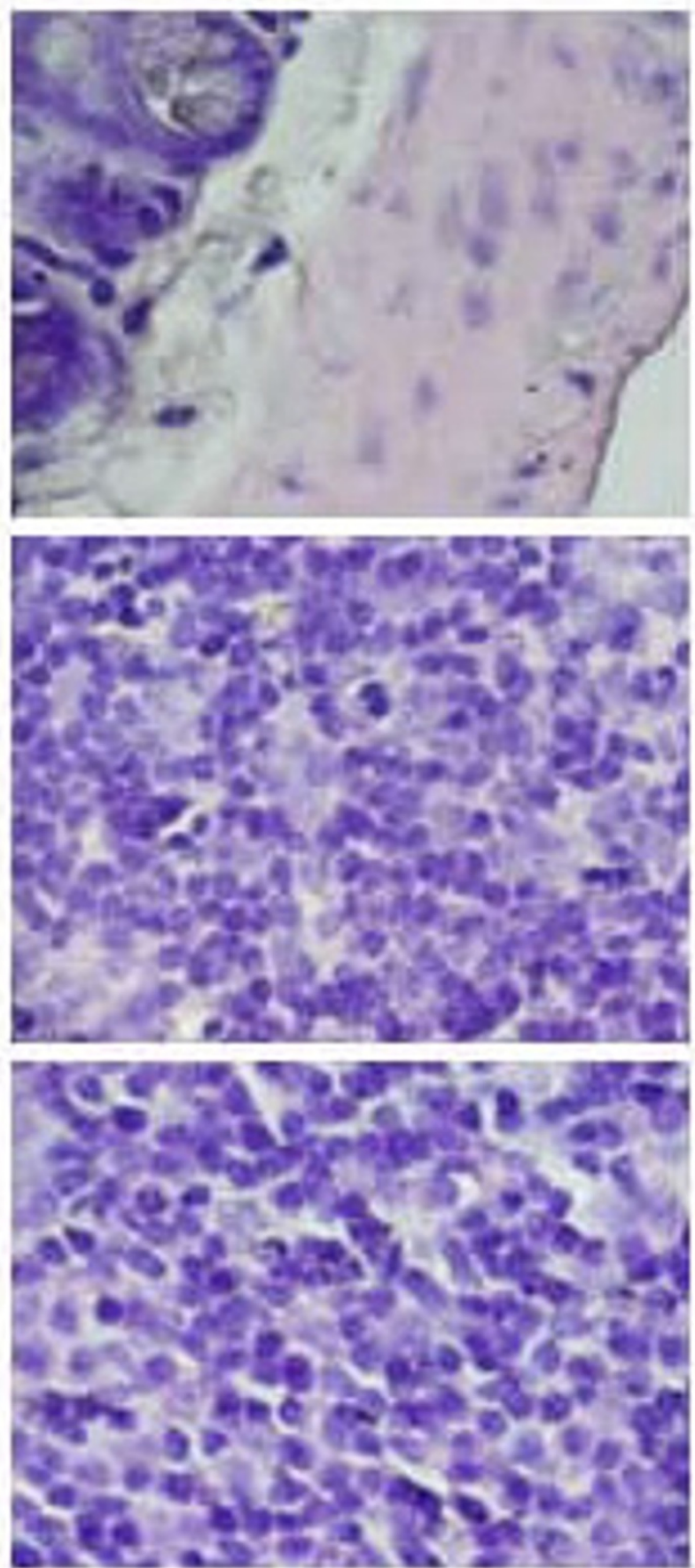

\section{Figure 5}

Histology of metastases in nude mice. The bowel containing the tumour nodules was paraffin-embedded, sectioned at 4 $\mu \mathrm{m}$ intervals and stained with hematoxylin-eosin. The left panels represent the lower magnification of the bowel with or without tumour nodules ( $\times 40$, P7 vs. P59). The squared regions in the left panels are enlarged in the right panels $(\times 400)$. 
manuscript. All authors have read and approved the final manuscript.

\section{Authors' information}

MI's current address: Cancer Cell Circuitry Laboratory, Institute of Biomedicine/Biochemistry and Genome-Scale Biology Program, Biomedicum Helsinki, University of Helsinki, Helsinki, Finland.

MM's current address: Department of Biomedical Science, Graduate School of Agricultural and Life Sciences, The University of Tokyo, Tokyo, Japan.

\section{Acknowledgements}

We would like to thank Drs. Kiyotaka Toshimori and Kenji Miyado for their valuable advice on our histological analysis and Dr. Junwen Qin for his technical assistance. This work was supported partly by a Grant-in Aid for Scientific Research (C) (1859/8I8 to YT) from the Ministry of Education, Culture, Sports, Science and Technology, partly by a grant from Kanzawa Medical Research Foundation (to YT) and Research on Child Health and Development (to HS) from the Ministry of Health, Labour and Welfare, Japan.

\section{References}

I. Nishi Y, Yanase T, Mu Y, Oba K, Ichino I, Saito M, Nomura M, Mukasa C, Okabe T, Goto K, Takayanagi R, Kashimura Y, Haji M, Nawata H: Establishment and characterization of a steroidogenic human granulosa-like tumor cell line, KGN, that expresses functional follicle-stimulating hormone receptor. Endocrinology 200I, I42:437-445.

2. Schumer ST, Cannistra SA: Granulosa cell tumor of the ovary. J Clin Oncol 2003, 21:1 I80-1 189.

3. Stuart GC, Dawson LM: Update on granulosa cell tumours of the ovary. Curr Opin Obstet Gynecol 2003, I 5:33-37.

4. Dorward AM, Shultz KL, Beamer WG: LH analog and dietary isoflavones support ovarian granulosa cell tumor development in a spontaneous mouse model. Endocr Relat Cancer 2007, 14:369-379.

5. Kurihara S, Hirakawa T, Amada S, Ariyoshi K, Nakano H: Inhibinproducing ovarian granulosa cell tumor as a cause of secondary amenorrhea: case report and review of the literature. J Obstet Gynaecol Res 2004, 30:439-443.

6. Robertson DM, Pruysers E, Jobling T: Inhibin as a diagnostic marker for ovarian cancer. Cancer Lett 2007, 249: I4-17.

7. Crew KD, Cohen MH, Smith DH, Tiersten AD, Feirt NM, Hershman DL: Long natural history of recurrent granulosa cell tumor of the ovary 23 years after initial diagnosis: a case report and review of the literature. Gynecol Oncol 2005, 96:235-240.

8. Villella J, Herrmann FR, Kaul S, Lele S, Marchetti D, Natiella J, Odunsi $\mathrm{K}$, Mhawech-Fauceglia P: Clinical and pathological predictive factors in women with adult-type granulosa cell tumor of the ovary. Int J Gynecol Pathol 2007, 26: I54-I59.

9. Staibano $S$, Franco R, Mezza E, Chieffi $P$, Sinisi A, Pasquali D, Errico ME, Nappi C, Tremolaterra F, Somma P, Mansueto G, De Rosa G: Loss of oestrogen receptor beta, high PCNA and p53 expression and aneuploidy as markers of worse prognosis in ovarian granulosa cell tumours. Histopathology 2003, 43:254-262.

10. East N, Alobaid A, Goffin F, Ouallouche K, Gauthier P: Granulosa cell tumour: a recurrence $\mathbf{4 0}$ years after initial diagnosis. J Obstet Gynaecol Can 2005, 27:363-364.

II. Russell DL, Salustri A: Extracellular matrix of the cumulusoocyte complex. Semin Reprod Med 2006, 24:217-227.

12. Thomas FH, Vanderhyden BC: Oocyte-granulosa cell interactions during mouse follicular development: regulation of kit ligand expression and its role in oocyte growth. Reprod Biol Endocrinol 2006, 4: 19.

13. Ishiwata I, Ishiwata C, Soma M, Kobayashi N, Ishikawa H: Establishment and characterization of an estrogen-producing human ovarian granulosa tumor cell line. I Natl Cancer Inst 1984, 72:789-800

14. Berg-Bakker CA van den, Hagemeijer A, Franken-Postma EM, Smit VT, Kuppen PJ, van Ravenswaay Claasen HH, Cornelisse CJ, Schrier $\mathrm{PI}$ : Establishment and characterization of 7 ovarian carcinoma cell lines and one granulosa tumor cell line: growth features and cytogenetics. Int J Cancer 1993, 53:6|3-620.

15. Lie BL, Leung E, Leung PC, Auersperg N: Long-term growth and steroidogenic potential of human granulosa-lutein cells immortalized with SV40 large T antigen. Mol Cell Endocrinol 1996, I 20:169-176.

16. Rainey WH, Sawetawan C, Shay JW, Michael MD, Mathis JM, Kutteh W, Byrd W, Carr BR: Transformation of human granulosa cells with the E6 and E7 regions of human papillomavirus. J Clin Endocrinol Metab 1994, 78:705-7I0.

17. Hosokawa K, Dantes A, Schere-Levy C, Barash A, Yoshida Y, Kotsuji F, Vlodavsky I, Amsterdam A: Induction of Ad4BP/SF-I, steroidogenic acute regulatory protein, and cytochrome P450scc enzyme system expression in newly established human granulosa cell lines. Endocrinology 1998, I39:4679-4687.

18. Kondo H, Kiguchi K, Okamura A, Okuma Y, lida T, Kobayashi Y, Takagi $M$, Ishizuka $B$, Ishiwata I: Establishment and characterization of a human ovarian granulosa tumor cell line (HSOGT). Hum Cell 2003, 16:123-129.

19. Lindgren V, Waggoner S, Rotmensch J: Monosomy 22 in two ovarian granulosa cell tumors. Cancer Genet Cytogenet 1996, 89:93-97.

20. Speleman F, Dermaut B, De Potter CR, Van Gele M, Van Roy N, De Paepe A, Laureys G: Monosomy 22 in a mixed germ cell-sex cord-stromal tumor of the ovary. Genes Chromosomes Cancer 1997, 19:192-194.

2I. Ito M, Muraki M, Takahashi Y, Imai M, Tsukui T, Yamakawa N, Nakagawa K, Ohgi S, Horikawa T, Iwasaki W, lida A, Nishi Y, Yanase T, Nawata H, Miyado K, Kono T, Hosoi Y, Saito H: Glutathione Stransferase thetal expressed in granulosa cells as a biomarker for oocyte quality in age-related infertility. Fertil Steril 2007 in press.

22. Cherian-Shaw M, Das R, Vandevoort CA, Chaffin CL: Regulation of steroidogenesis by $\mathrm{p} 53$ in macaque granulosa cells and H295R human adrenocortical cells. Endocrinology 2004, 145:5734-5744.

23. Jain S, Chakraborty G, Bulbule A, Kaur R, Kundu GC: Osteopontin: an emerging therapeutic target for anticancer therapy. Expert Opin Ther Targets 2007, I I:81-90.

24. Sjostrom J, Blomqvist C, von Boguslawski K, Bengtsson NO, Mjaaland I, Malmstrom P, Ostenstadt B, Wist E, Valvere V, Takayama S, Reed JC, Saksela E: The predictive value of bcl-2, bax, bcl-xL, bag-I, fas, and fasL for chemotherapy response in advanced breast cancer. Clin Cancer Res 2002, 8:8I I-8I6.

25. Hussein-Fikret S, Fuller PJ: Expression of nuclear receptor coregulators in ovarian stromal and epithelial tumours. Mol Cell Endocrinol 2005, 229:149-160.

26. Chu S, Nishi Y, Yanase T, Nawata H, Fuller PJ: Transrepression of estrogen receptor beta signaling by nuclear factor-kappab in ovarian granulosa cells. Mol Endocrinol 2004, 18:1919-1928.

27. Drubin DA, Clawson GA: Spontaneous transformation of an immortalized hepatocyte cell line: potential role of a nuclear protease. Cancer Lett 2004, 2 1 3:39-48.

28. Gregoire L, Rabah R, Schmelz EM, Munkarah A, Roberts PC, Lancaster WD: Spontaneous malignant transformation of human ovarian surface epithelial cells in vitro. Clin Cancer Res 200I, 7:4280-4287.

29. Scholl FA, Betts DR, Niggli FK, Schafer BW: Molecular features of a human rhabdomyosarcoma cell line with spontaneous metastatic progression. Br J Cancer 2000, 82:1239-1245.

30. Sun FX, Sasson AR, Jiang P, An Z, Gamagami R, Li L, Moossa AR, Hoffman RM: An ultra-metastatic model of human colon cancer in nude mice. Clin Exp Metastasis 1999, I7:4I-48.

\section{Pre-publication history}

The pre-publication history for this paper can be accessed here:

http://www.biomedcentral.com/1471-2407/8/319/pre pub 